\title{
Acute wound management: revisiting the approach to assessment, irrigation, and closure considerations
}

\author{
Bret A. Nicks • Elizabeth A. Ayello • Kevin Woo • \\ Diane Nitzki-George $\cdot$ R. Gary Sibbald
}

Received: 26 April 2010 / Accepted: 30 June 2010 /Published online: 27 August 2010

(C) Springer-Verlag London Ltd 2010

\begin{abstract}
Background As millions of emergency department (ED) visits each year include wound care, emergency care providers must remain experts in acute wound management. The variety of acute wounds presenting to the ED challenge
\end{abstract}

The views expressed in this paper are those of the author(s) and not those of the editors, editorial board or publisher.

\author{
B. A. Nicks $(\square)$ \\ Department of Emergency Medicine, \\ Wake Forest University Health Sciences, \\ Medical Center Boulevard, \\ Winston-Salem, NC 27157, USA \\ e-mail: bnicks@wfubmc.edu \\ E. A. Ayello \\ Ayello, Harris \& Associates, Inc., \\ Copake, NY, USA \\ E. A. Ayello $\cdot$ K. Woo $\cdot$ R. G. Sibbald \\ University of Toronto, \\ Toronto, Ontario, Canada \\ E. A. Ayello \\ Excelsior College School of Nursing, \\ Albany, NY, USA \\ K. Woo \\ Women's College Hospital, \\ Toronto, Canada \\ D. Nitzki-George \\ Division of Clinical Pharmacology, \\ NorthShore University HealthSystem, \\ Chicago, IL, USA \\ R. G. Sibbald \\ Wound Healing Clinic \& Medical Education, \\ Women's College Hospital, \\ Toronto, Ontario, Canada \\ R. G. Sibbald \\ World Union of Wound Healing Societies, \\ Toronto, Canada
}

the physician to select the most appropriate management to facilitate healing. A complete wound history along with anatomic and specific medical considerations for each patient provides the basis of decision making for wound management. It is essential to apply an evidence-based approach and consider each wound individually in order to create the optimal conditions for wound healing.

Aims A comprehensive evidence-based approach to acute wound management is an essential skill set for any emergency physician or acute care practitioner. This review provides an overview of current evidence and addresses frequent pitfalls.

Methods A systematic review of the literature for acute wound management was performed.

Results A structured MEDLINE search was performed regarding acute wound management including established wound care guidelines. The data obtained provided the framework for evidence-based recommendations and current best practices for wound care.

Conclusion Acute wound management varies based on the wound location and characteristics. No single approach can be applied to all wounds; however, a systematic approach to acute wound care integrated with current best practices provides the framework for exceptional wound management.

Keywords Acute tissue injury - Wound assessment . Wound irrigation · Wound closure - Assessment · Cleansing · Closure Irrigation $\cdot$ Wound

\section{Introduction}

The emergency department (ED) is frequently the presenting location for acute wounds, which is appropriate given its convenience, resources, and expertise. Acute wounds are often precipitated by trauma, such as burns, lacerations, or abrasions [1]. As the historical and clinical features 
surrounding the cutaneous injury process differ, wounds must be evaluated and treated individually.

Without proper cleansing and wound care, these acute wounds can lead to complications, such as poor healing and infection. Optimizing wound healing through proper acute wound management involves removal of harmful debris/ necrotic tissue, exploration for underlying injuries, control of bacterial burden and appropriate closure. A comprehensive evidence-based approach to acute wound management is an essential skill-set for any ED physician or acute care practitioner.

\section{Discussion}

\section{Definitions}

Primary closure, also known as healing by first intention, represents closure of a wound at the time of initial presentation. Wound edges are approximated with suture, adhesives, staples, or strips after appropriate wound management techniques are applied.

Delayed primary closure represents a delay in wound closure for approximately 3-5 days. This is ideal for delayed presentations or for wound infection concerns. If there are no signs of infection and the wound margins appear healthy, removal of devitalized tissue and subsequent primary closure is appropriate.

Healing by secondary intention represents those wounds that are allowed to heal through contraction-a natural, unaided physiologic property. While appropriate wound management practices are involved, no attempt is made to aid wound closure.

\section{Epidemiology}

In 2006, 11 million traumatic wounds were managed through the ED in the US [1]. Young adult males account for the majority of lacerations with $35 \%$ in the upper extremities and nearly $50 \%$ in the head and neck region (Table 1) $[1,2]$. Of those presenting to the ED with acute wounds, primary concerns relate to cosmesis, minimizing the pain of repair, preventing infection, and restoring normal function [3].

Table 1 Type and frequency of wounds per ED admissions [1]

\begin{tabular}{ll}
\hline Burns & $0.4 \%$ \\
Open wounds, unspecified & $5.2 \%$ \\
Other injuries & $1.4 \%$ \\
Superficial injury & $1.2 \%$ \\
Surgical and medical complications & $0.4 \%$ \\
Trauma complications and unspecified injuries & $1.6 \%$ \\
Total wound care (\% of ED admissions) & $10.2 \%$ \\
\hline
\end{tabular}

Anatomy/physiology

The epidermis, dermis, subcutaneous tissues, and fascia are the layers most frequently involved with acute lacerations. In normal tissue, the epidermis provides the barrier protecting the integumentary system. With simple laceration repair, the epidermis and dermis are closed as one layer-with the dermal closure accounting for the strength. The subcutaneous (adipose) layer contains neurovascular structures, but provides little support to the closure. Assessment for associated tendon, vascular, and facial involvement is essential, as these wounds typically require more complex evaluation, consultation, and repair by the appropriate specialist.

Normal acute wounds usually progress through an orderly sequential trajectory of hemostasis, proliferation, maturation, and remodeling [4]. After initial injury to the dermal tissue, hemostasis is established by platelet aggregation, fibrin clot formation, and the subsequent coagulation pathways. Local migration of neutrophils and macrophages initiates an acute inflammatory response to help prevent microbial overgrowth as well as initiate wound healing. During the proliferative phase, deficiencies in soft tissue are replaced with healthy new granulation tissue and matrix material. As healing progresses, the majority of type III collagen formed by fibroblasts is converted to type I collagen to enhance soft tissue strength and integrity [5].

To ensure the normal physiology of healing, wounds must have sufficient blood supply. Inflammation, infection, or residual debris may delay or prevent adequate healing. As healing occurs, wound tensile strength will approach $20 \%$ at 3 weeks and $60 \%$ by 4 months [4].

\section{Acute assessment}

As with all emergency presentations, patient resuscitation and stabilization are of paramount importance. Aside from those requiring immediate intervention due to significant hemorrhage, most wounds are evaluated during the secondary assessment. Wound irrigation and exploration in a well-lighted area may help identify the site of bleeding, allow for immediate intervention, and identify any emergency surgical concerns. In addition to volume loss from hemorrhage, wounds involving more than $10 \%$ of the body surface area are associated with loss of excess extracellular fluid, may become life-threatening, and often need inpatient management [6].

The primary goals for wound care are to attain a functional closure, decrease potential risk for infection, and minimize scar formation [6]. As such, a complete patient history is needed to determine the outcome risks for all wounds, including risks for and type of potential contamination, activity at time of injury, functional 
changes, and any comorbid illnesses that may prevent or decrease normal healing. Injury to and through the epidermis can allow for bacterial migration and subsequent inflammation and infection if not appropriately managed. Associated risk factors for infection are increased age, diabetes, increased laceration width, wound contamination, or the presence of a foreign body [2]. In addition, tetanus, medication and allergy history should be obtained prior to initiation of wound management.

The time from injury to acute wound management is an essential consideration for appropriate wound closure. Studies by Berk, Chisholm, and Lammers have provided a framework for a well-defined closure period [7-9]. In general, 6-10 $\mathrm{h}$ is an appropriate time period for extremity laceration repair, with $10-12 \mathrm{~h}$ for the more vascular face and scalp. However, these time suggestions require integration with clinical judgment and infection potential.

Wound debris can act as both an infectious nidus and toxic contaminant [10]. Wounds in which soil or dirt are embedded are considered contaminated at the time of injury and may need to be left open if adequate debridement is uncertain, or may require a more aggressive operative washout. A deeply contaminated wound that is not completely clean has an increased risk of developing an anaerobic infection if closed [6].

The physical examination of a wound requires assessment of location, length, width, depth, type of tissue in the wound bed, neurovascular and functional status of surrounding structures, and associated contaminants. If neurovascular compromise is present or if deep structures such as tendons, muscles, or bones are involved, specialty consultation may be warranted. It is imperative to assess all wounds through a full range of motion, paying particular attention to the position at the time of injury. For those delayed presentations, infection is expected in cases of secondary abscess, purulent drainage, or if the skin has a dimpled appearance $>1 \mathrm{~cm}$ beyond the wound edge. Wounds that appear dry, gangrenous, or have demarcated gangrene are non-healable due to ischemia and other secondary factors.

\section{Managing wound pain}

Proper wound evaluation and cleansing can be a painful process that may cause less physical and emotional damage if anesthetics are used. Current options include topical, local injection, and regional anesthetics. The American Academy of Pediatrics recommends the use of topical anesthestics, such as LET (4\% lidocaine, $0.1 \%$ epinephrine, $0.5 \%$ tetracaine), for simple lacerations of the head, neck, and extremities, or trunk $<5 \mathrm{~cm}$ in length [11]. Systemic toxicity can occur through excessive absorption of topical anesthetics; however, this can be minimized by avoiding mucosal membranes and large open wounds [12]. Additional studies have shown the gel formulation can provide better area containment and improved anesthesia [13]. Assessment of the wound prior to the onset of repair is essential since topical preparations may not anesthetize the most distal areas involved in repair. Contamination of the skin may affect absorption and efficacy, especially if the contaminant interacts with the drug [14].

While there are numerous commercially available topical anesthetic agents, most of these require 10 to $30 \mathrm{~min}$ to become effective. The combination of lidocaine/prilocaine may have a delayed onset of 1 to $2 \mathrm{~h}$ [15]. If a more rapid anesthetic response is needed, injectable lidocaine (1\%), bupivicaine $(0.25 \%)$, or procaine $(1 \%)$ is commonly used. While these drugs remain the mainstay of anesthesia for cutaneous repair, the associated pain on injection remains a major drawback. Numerous studies have shown that buffering the lidocaine solution ( $1 \mathrm{ml}$ of sodium bicarbonate to $9 \mathrm{ml}$ of lidocaine), warming the solution to body temperature, and injecting slowly through a $27-30$ gauge needle will decrease the pain on injection $[16,17]$. Bicarbonate increases the spread of the anesthetic and shortens the time to onset. Anesthetic should be injected through non-contaminated wound margins. Bupivicaine provides duration of action of 4-8 $\mathrm{h}$ compared to the $1-2 \mathrm{~h}$ when using lidocaine. If epinephrine is added, the duration of action is prolonged, but this should only be used in areas with adequate vascular supply. Epinephrine should be avoided when injecting directly into areas prone to ischemia due to variable blood supply, such as fingers, toes, the distal nose tip, pinna, and penis.

Application of a regional nerve block may have preferential benefits in areas where injection of local anesthesia is limited by anatomic considerations, concern for distortion of the tissues being closed, or benefit of proximal blockade to maximize site anesthesia when the distribution is appropriate. Utilization of a 25- to 27-gauge needle is preferred. Neurovascular assessment prior to the onset of the block is essential. The dose of each drug is limited, and epinephrine is included in the injection when higher doses are needed (Table 2).

Table 2 Dose limitation of locally injected anesthetics

\begin{tabular}{ll}
\hline Drug & Maximum dose \\
\hline Bupivacaine $0.25 \%(2.5 \mathrm{mg} / \mathrm{ml})$ & $2 \mathrm{mg} / \mathrm{kg}$ \\
Bupivacaine $0.25 \%$ with epinephrine & $3 \mathrm{mg} / \mathrm{kg}$ \\
Lidocaine $1 \%(10 \mathrm{mg} / \mathrm{ml})$ & $4.5 \mathrm{mg} / \mathrm{kg}$ \\
Lidocaine $1 \%$ with epinephrine & $7 \mathrm{mg} / \mathrm{kg}$ \\
Procaine $1 \%(10 \mathrm{mg} / \mathrm{ml})$ & $7 \mathrm{mg} / \mathrm{kg}$ \\
Procaine $1 \%$ with epinephrine & $9 \mathrm{mg} / \mathrm{kg}$ \\
\hline
\end{tabular}


Allergy to local anesthesia may occur and represents a combination of immediate and delayed hypersensitivity reactions [18]. Although topical anesthetics are not typically associated with allergy, contact dermatitis and irritation have been reported. While rare, cases of seizure and sudden cardiac arrest have been reported after the use of TAC (tetracaine, epinephrine, and cocaine) solutions on or near mucous membranes $[19,20]$. The most likely causes of allergic reactions are either the preservatives or the ester type of anesthetic agents. Bupivicaine, lidocaine, and prilocaine are classified as amides, whereas benzocaine, cocaine, procaine, and tetracaine are classified as esters [18]. Crossreactivity is not seen between esters and amides, making allergy history essential before anesthesia is provided.

Cleansing techniques

Proper wound preparation improves healing and outcomes [21]. While evidence-based recommendations for wound care exist, many practitioners continue to treat wounds based on personal preference-some employing unnecessary or possibly detrimental techniques [21]. Acute wound cleansing incorporates three different techniques: compresses, irrigation, and soaking (Table 3). The technique used and degree of cleansing depend on the type of injury, environmental considerations, and condition of the wound on presentation.

\section{Compresses}

Cleansing with compresses is done by gently pressing moist gauze on the wound to remove gross surface debris, while also improving wound moisture balance [21]. For wounds presenting with dry, imbedded debris or with desiccated tissue, brief soaking will hydrate the wound, soften the underlying tissue, and enhance the irrigation process [22].

\section{Pressure irrigation}

Wound irrigation is arguably the most important step for optimizing wound healing as long as there is sufficient pressure and volume. Irrigation pressure recommendations that are often cited in the literature come mostly from studies in chronic wounds (such as pressure ulcers). Many studies either failed to describe how pressure was measured or identify the actual realized pressure on the tissues. Within the realm of acute wound management, the term 'high pressure' irrigation is frequently used to describe the best practice for wound irrigation. However, it is important to understand that this term reflects a wide range of pressures and a paucity of well-supported literature as to the deliverable irrigant pressure.

Classically, equipment used for irrigation has included bulb syringes, syringes with an attached needle or catheter, intravenous or irrigation fluid in plastic containers with a pour cap or nozzle, and pressure canisters. Puncturing containers of irrigation fluid and manually squeezing are inadequate for pressure irrigation [23]. Studies have shown that when using a syringe with an attached 19-gauge needle, pressures range from 11 to $31 \mathrm{psi-however,} \mathrm{only}$ 8 psi may reach the wound [23, 24]. Current medical devices have been designed to provide a more consistent and measurable application of wound irrigation pressure. Clinicians currently believe that these advances may provide a better approach to wound cleansing [25].

There is some evidence that very high pressure irrigation may actually increase infection rates due to further tissue damage. This is particularly evident in highly vascularized wounds, such as the face and scalp [2]. A study by

Table 3 Methods of wound cleansing

\begin{tabular}{|c|c|c|c|}
\hline Cleansing method & Description & Purpose & Potential risks \\
\hline Compress & $\begin{array}{l}\text { Gently pressing excess moisture from a } \\
\text { moistened gauze/cloth applied to the } \\
\text { wound and removing after wound contact } \\
\text { to remove surface debris. The cycle can } \\
\text { then be repeated }\end{array}$ & $\begin{array}{l}\text { Astringent action } \\
\text { (coagulate protein) to } \\
\text { remove surface debris } \\
\text { from the wound }\end{array}$ & $\begin{array}{l}\text { - The compress can stick to the wound } \\
\text { surface or there may be local pain from } \\
\text { application or removal } \\
\text { - Faulty technique can introduce infection }\end{array}$ \\
\hline Irrigation & $\begin{array}{l}\text { Steady flow of solution across } \\
\text { wound surface }\end{array}$ & $\begin{array}{l}\text { Hydrate the wound } \\
\text { Remove deeper debris } \\
\text { Assist with visual exam }\end{array}$ & $\begin{array}{l}\text { - More trauma if pressure too high } \\
\text { - Splash back } \\
\text { - High pressure may drive bacteria into } \\
\text { deeper compartments }\end{array}$ \\
\hline Soaking & $\begin{array}{l}\text { Immersion of wound in solution applying } \\
\text { an over-hydrated cloth or gauze to the } \\
\text { wound surface (no removal of excess } \\
\text { moisture prior to application) }\end{array}$ & $\begin{array}{l}\text { Hydrate the wound } \\
\text { Allow for physical } \\
\text { removal of debris }\end{array}$ & $\begin{array}{l}\text { - Disruption of moisture balance } \\
\text { - Maceration of surrounding skin } \\
\text { - Impaired healing with introduction } \\
\text { of bacteria from immersion fluid }\end{array}$ \\
\hline
\end{tabular}


Chisholm found no difference in infection rates of lacerations that required closures when irrigation was done using a pressure canister compared to a syringe/needle irrigation (5.0\% vs. 3.6\%; $P=0.05$ ) [26]. Longmire found that high pressures of 13 psi, generated by using a needle and syringe, were effective in reducing inflammation and infection when compared to irrigation using a bulb syringe associated with lower pressures [24]. Pressures of $8-12$ psi in the wound are believed to overcome the adhesive forces of the introduced bacterium [24, 26]. However, both of these studies were limited by the inability to measure consistent pressures across the tissue beds being irrigated.

\section{Irrigation volume}

Irrigation volumes of 50 to $100 \mathrm{ml}$ per $\mathrm{cm}$ of laceration length have been reported $[9,26]$. The volume of irrigation should be adjusted to the wound characteristics and degree of contamination. All wound surfaces should be irrigated and may require pulling open the wound edges and flaps for exposure [9]. Repeat irrigation has been recommended after any re-examination of the wound [27].

\section{Irrigation solution}

Decontamination, including brushing off any dry chemicals prior to copious irrigation, is an essential part of the initial wound management. It is important to consider toxicological exposure as it relates to wound irrigation. Antiseptic solutions, such as povidone-iodine, chlorhexidine, and hydrogen peroxide, are toxic to tissues and may impede acute wound healing [25]. The current literature supports no difference in ED wound infection rates when using potable tap water versus saline in adult and pediatric populations [28]. Further, studies comparing saline irrigation with diluted $1 \%$ povidone-iodine have shown no difference in infection rates $[26,29,30]$. A study of chemical burns $(\mathrm{N}=$ 24) recommended copious amounts of potable tap water or saline for irrigation and decontamination [31].

\section{Debridement}

Debridement may be necessary to remove any devitalized tissue or to facilitate improved wound closure. In general, devitalized tissue is removed using a sharp/surgical debridement using a scalpel or scissors [32]. In addition, surgical debridement produces perpendicular (rather than beveled) wound edges. On occasion, sharp surgical wound debridement in the operating room may be required [32].

Acute wounds without intrinsic, extrinsic, or mechanical damage may be debrided and closed immediately. Wounds that are left to heal by secondary intention will need follow- up for wound assessment and possible secondary debridement to ensure proper healing.

\section{Antibiotics/tetanus}

Current CDC guidelines recommend a tetanus vaccine for wound management based on vaccination history and wound severity. All patients with an unknown vaccination history or who have received fewer than three doses should receive a tetanus diphtheria vaccine (Td). Inadequately vaccinated patients with anything other than a clean, minor wound should also receive tetanus immune globulin (TIG). Patients who have received three or more tetanus vaccines prior to the injury only need $\mathrm{Td}$ vaccination if their previous dose was more than 10 years ago for clean, minor wounds or 5 years for other wounds (Table 4) [33].

The need for antibiotic therapy should be based on the wound characteristics as well as the closure method. Wounds that are more likely to become infected include bites of the hand or face, deep puncture wounds, and lacerations to lymphedematous tissue as well as those presenting with pus or contaminated with saliva, feces, or vaginal secretions [34]. Patients who are immunocompromised, with prosthetic joints, at risk for endocarditis, or receiving corticosteroid therapy should be considered for antibiotic therapy $[34,35]$. Although $6 \mathrm{~h}$ is considered the "golden" time between injury and risk for infection, $3 \mathrm{~h}$ is a more conservative recommendation for deciding to start antibiotic therapy when appropriate[36].

A controlled study by Ichikawa found baseline wound infection rates that varied by degree of contamination: $2.6 \%$ in clean-contaminated, $5.8 \%$ in contaminated, and $20.8 \%$ in dirty wounds [37]. In a study of 1,142 acute wounds, Lammers found an overall infection rate of $7.2 \%$, although rates vary based on location [9]. Scalp wounds had an infection rate of $1.7 \%$, whereas thigh and leg wounds were as high as $23 \%$ (Table 5). The most predictive factors for wound infection were wound location, wound age, depth, configuration, contamination, and patient age [9]. Infection rates also correlate well to physician perception of risk [9]. Antibiotic selection should be based

Table 4 Tetanus wound management [33]

\begin{tabular}{lllll}
\hline & \multicolumn{2}{l}{ Clean, minor wounds } & \multicolumn{2}{l}{ All other wounds } \\
\hline Vaccination history & Td & TIG & Td & TIG \\
Unknown or $<3$ doses & Yes & No & Yes & Yes \\
$\geq 3$ doses & No* & No & No** & No \\
\hline
\end{tabular}

Td, tetanus diphtheria; TIG, tetanus immune globulin

$*$ Yes, if $>10$ years since last dose

$* *$ Yes, if $>5$ years since last dose 
Table 5 Wound location and infection rates [9]

\begin{tabular}{ll}
\hline Location & Infection rate (n) \\
\hline Arm/forearm & $15.3 \%(157)$ \\
Back & $8.3 \%(12)$ \\
Chest/abdomen & $11.8 \%(17)$ \\
Ear/nose & $3.6 \%(28)$ \\
Face & $3.9 \%(383)$ \\
Foot/toe & $12.5 \%(21)$ \\
Hand/finger & $5.7 \%(192)$ \\
Scalp & $1.7 \%(233)$ \\
Thigh/leg & $23.0 \%(87)$ \\
\hline
\end{tabular}

Adapted with permission from Elsevier Ltd

on local patterns of resistance and microbial risks based on type of injury.

\section{Closure considerations}

Primary wound closure incorporates suture, tissue adhesive, staples, and strips individually or in conjunction with each other. Sutures remain the most common closure technique, supported by years of refinement and safety. Low to medium tension wounds are closed by percutaneous sutures using a low reactive material including monofilament sutures such as nylon or polypropylene. Surgical strips, only appropriate for wounds with low tension, have low reactivity and are frequently used in conjunction with another closure method. Wounds that are either stapled or glued appear to have similar outcomes, but glues are less painful and placed more quickly [38]. Tissue adhesives are associated with significantly more dehiscence than sutures and are most appropriate for non-mucosal facial wounds and lowtension extremity wounds [38]. Complex wounds need to be closed in two layers using absorbable sutures such as polydioxanone (PDS), polyglycolic acid (Dexon-Plus), or polyglactin 910 (Vicryl).

Staples are faster to place and less expensive than sutures. When wounds are appropriately prepared and the site is correctly selected, staples tend to have lower wound infection rates and fewer complications [39]. If used on the scalp, staples are not associated with any greater scar formation than sutures. However, if left in place too long, staples may result in greater scar formation [39]. Staples are commonly used on the scalp, trunk, and extremities - areas less prone to cosmetic considerations.

Healing heavily contaminated wounds

Wounds that are heavily contaminated may need delayed primary closure to minimize the risk of infection. These wounds are cleaned, debrided, and dressed with a moist dressing, then covered to prevent further contamination. The moist dressing is typically changed daily and the wound reassessed after 3 to 4 days. If no signs of infection are present upon re-examination, secondary closure can be performed. Extremely dirty wounds may benefit from daily cleansing and dressing changes for the first 3 to 5 days prior to closure.

In circumstances where secondary closure cannot be performed, healing by secondary intent is generally used. No attempt for aided wound closure is provided.

\section{Aftercare}

There are several factors that directly impact wound outcome. A moist wound healing environment has been shown to help prevent cell dehydration and death, promote angiogenesis, and improve phagocytosis and growth factor elaboration. Moisture also improves the rate of re-epithelialization, reduces pain, and improves the cosmetic outcome [40]. It is essential that appropriate wound dressing, patient education related to wound care, appropriate environmental considerations, and clinical follow-up are discussed. In general, referral to the patient's primary care physician or outpatient clinic will be necessary for evaluation of the healing process or follow-up depending on the closure technique.

Current literature, mainly from plastic surgery and dermatology, recommends the use of sunblock products on a new wound for 3-6 months after epithelialization (which is typically completed within $48-72 \mathrm{~h}$ ). This should be reiterated to the patient during any wound check visits, but especially during suture or staple removal [41]. The choice of dressing applied to a wound directly impacts both wound healing and scarring. This is accomplished with application of dressings that provide a warm, moist environment. While the value of topical antibiotics is debated, aside from possible contact dermatitis, its application may create the appropriate conditions needed for epithelialization.

Pitfalls

- Not providing adequate wound care information to the patients

- Not advocating for the patient to maintain a moist wound environment

- Not using universal precautions when irrigating, cleansing, or closing wounds

- Irrigating clean wounds unnecessarily and excessively in highly vascularized locations

- Not considering the wound characteristics and circumstances when determining the best closure approach 


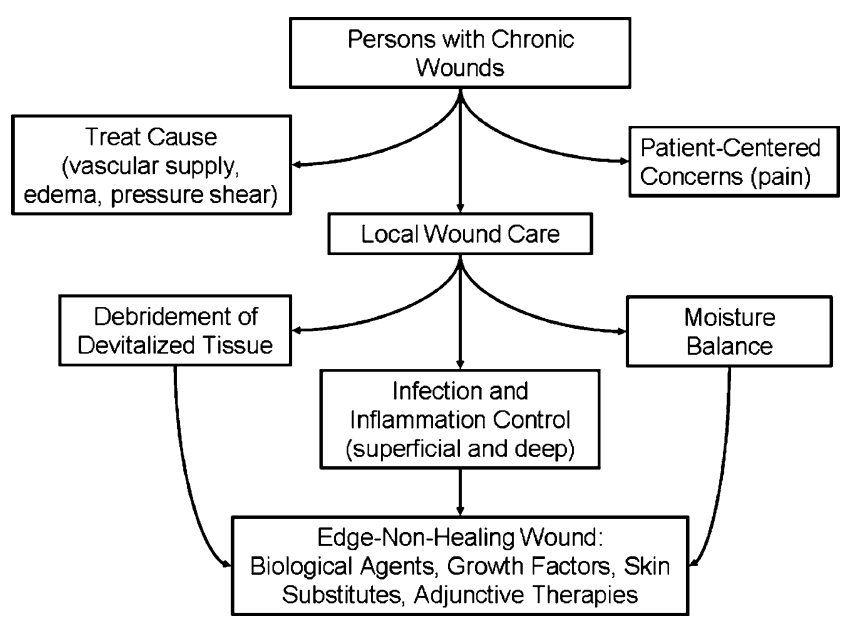

Fig. 1 Wound bed preparation and DIM-E model [42-44]

\section{Acute care of chronic wounds}

Chronic wounds, including diabetic foot ulcers, venous leg ulcers, and pressure ulcers, are complex and often present to the ED. The wound bed preparation (WBP) model is used to systematically manage chronic wounds and optimize achievable patient outcomes (Fig. 1) [42-44]. The three important components of local chronic wound care are represented by the letters DIM: debridement, infection and inflammation control, and moisture balance. Advanced active therapies are used to stimulate the non-advancing edge or promote healing of the stalled wound by other mechanisms.

In order to treat a diabetic foot ulcer, it is important to consider the VIPS: assess vascular supply; treat infections; redistribute plantar pressure with shoes, orthotics or special devices; use sharp surgical debridement if the wound is healable.

Patients with venous leg ulcers require bandaging to heal and stockings to maintain circulation. An ankle brachial pressure index greater than 0.8 requires high-compression bandaging, whereas patients with values between 0.6 and 0.8 can be bandaged with modified compression. Patients with pressure ulcers need pressure reduction through assessment of beds, mattresses, and seating. In addition to pressure, other issues need to be addressed including excess moisture (urinary and fecal incontinence), nutrition, mobility, and friction and shear.

Additional wound considerations

The non-healable wound has either inadequate vasculature or a coexisting factor that prohibits the healing process. In general, immunosuppressive therapy, tissue ischemia, poor wound repair, and other wound characteristics (Table 6) can all present risk factors for poor wound outcomes [45]. Treatment of wounds with inadequate vascular supply or certain coexisting medical conditions heal by secondary intention and require longterm maintenance.

Wound depth is a factor that affects the rate of healing. Superficial wounds in otherwise healthy people, involving only the epidermis and papillary dermis, are expected to heal within 10 days with appropriate treatment and no complications [21, 44]. Partial thickness wounds, such as a skin graft donor site, normally take up to 21 days to heal [8, 21, 43]. Full thickness wounds undergo two stages of healing. Primary healing of the deep tissue within 7 days post-injury allows for secondary healing through re-epithelialization and contraction.

\section{Conclusion}

The variety of acute wounds presenting to the ED challenges the physician to select the most appropriate management to facilitate healing. A complete wound history along with knowledge of the healing potential of the wound, as it relates to the specific medical and environmental considerations for each patient, provides the basis of decision making for wound management. It is essential to consider each wound individually in order to create the optimal conditions for wound healing.

Table 6 Risk factors for poor wound repair outcome [45]

\begin{tabular}{llll}
\hline Immunosuppression & Tissue ischemia & Poor wound repair & Wound factors \\
\hline - Chemotherapeutic agents & - Anemia & • Connective tissue disorders & $\bullet$ Contamination \\
- Chronic renal failure & $\bullet$ Peripheral vascular disease & $\bullet$ Elderly & $\bullet$ Crush injuries \\
- Congenital immunodeficiencies & $\bullet$ Vasculitis & $\bullet$ Malnourished & - Foreign bodies \\
- Diabetes & & & - Location \\
- Hematologic malignancies & & \\
- Steroids & & \\
\hline
\end{tabular}

Adapted from Tintinalli’s Emergency Medicine. Reprinted with permission from The McGraw-Hill Companies, Inc 
Acknowledgments This article was supported by funding from Baxter Healthcare Corporation, Deerfield, IL.

Conflicts of interest Dr. Nicks has nothing to disclose other than educational grant assistance for this article. Dr. Sibbald discloses having consulting agreements with: Molnlycke, Coloplast, KCI, Systagenix, Convatec, Covidien, $3 \mathrm{M}$, Medline, and the Government of Ontario. Dr. Ayello discloses having consulting agreements with: Molnlycke, Coloplast, KCI, 3 M Health, Hill-Rom, Medline, Healthpoint, and the New Jersey Hospital Association. Dr. Woo discloses having consulting agreements with: Molnlycke, Coloplast, KCI, $3 \mathrm{M}$ Health, Hill-Rom, Medline, and Healthpoint.

\section{References}

1. Pitts SR, Niska RW, Xu J, Burt CW (2008) National hospital ambulatory medical care survey: 2006 Emergency department summary. National Health Care Statistics 6(7):1-40

2. Hollander JE, Singer AJ, Valentine SM, Shofer FS (2001) Risk factors for infection in patients with traumatic lacerations. Acad Emerg Med 8(7):716-720

3. Singer AJ, Dagum AB (2008) Current management of acute cutaneous wounds. N Engl J Med 359(10):1037-1046

4. Barbul A (2005) Wound healing. In: Brunicardi FC, Andersen DK, Billiar TR et al (eds) Schwartz's principles of surgery, Eighthth edn. The McGraw-Hill Companies, Inc, Columbus, pp 165-182

5. Woo K, Ayello EA, Sibbald RG (2007) The edge effect: current therapeutic options to advance the wound edge. Adv Skin Wound Care 20(2):99-117

6. Percival NJ (2002) Classification of wounds and their management. Surgery 20(5):114-117

7. Berk WA, Welch RD, Bock BF (1992) Controversial issues in clinical management of the simple wound. Ann Emerg Med 21 (1):72-80

8. Chisholm CD (1992) Wound evaluation and cleansing. Emerg Med Clin North Am 10(4):665-672

9. Lammers RL, Hudson DL, Seaman ME (2003) Prediction of traumatic wound infection with a neural network-derived decision model. Am J Emerg Med 21(1):1-7

10. Frank M, Schmucker U, Hinz P, Zach A, Ekkernkamp A, Matthes G (2008) Not another 4th of July report: uncommon blast injuries to the hand. Emerg Med J 25(2):93-97

11. Zempsky WT, Cravero JP (2004) Relief of pain and anxiety in pediatric patients in emergency medical systems. Pediatrics 114 (5):1348-1356

12. Bonadio WA (1996) Safe and effective method for application of tetracaine, adrenaline, and cocaine to oral lacerations. Ann Emerg Med 28(4):396-398

13. Ernst AA, Marvez-Valls E, Nick TG, Mills T, Minvielle L, Houry D (1997) Topical lidocaine adrenaline tetracaine (LAT gel) versus injectable buffered lidocaine for local anesthesia in laceration repair. West J Med 167(2):79-81

14. Railan D, Alster TS (2007) Use of topical lidocaine for cosmetic dermatologic procedures. J Drugs Dermatol 6 (11):1104-1108

15. Kundu S, Achar S (2002) Principles of office anesthesia: part II. Topical anesthesia. Am Fam Physician 66(1):99-102

16. Scarfone RJ, Jasani M, Gracely EJ (1998) Pain of local anesthetics: Rate of administration and buffering. Ann Emerg Med 31(1):36-40
17. Brogan GX, Singer AJ, Valentine SM et al (1997) Comparison of wound infection rates using plain versus buffered lidocaine for anesthesia of traumatic wounds. Am J Emerg Med 15:25-28

18. Thyssen JP, Menné T, Elberling J, Plaschke P, Johansen JD (2008) Hypersensitivity to local anaesthetics-update and proposal of evaluation algorithm. Contact Dermat 59(2):69-78

19. Daya MR, Burton BT, Schleiss MR, DiLiberti JH (1988) Recurrent seizures following mucosal application of TAC. Ann Emerg Med 17(6):646-648

20. Dailey RH (1988) Fatality secondary to misuse of TAC solution. Ann Emerg Med 17(2):159-160

21. Howell JM, Chisholm CD (1992) Outpatient wound preparation and care: a national survey. Ann Emerg Med 21(8):976-981

22. Pfaff JA, Moore GP (2007) Reducing risk in emergency department wound management. Emerg Med Clin N Am 25:189-201

23. Singer AJ, Hollander JE, Subramanian S, Malhotra AK, Villez PA (1994) Pressure dynamics of various irrigation techniques commonly used in the emergency department. Ann Emerg Med 24 (1):36-40

24. Longmire AW, Broom LA, Burch J (1987) Wound infection following high-pressure syringe and needle irrigation. Am J Emerg Med 5(2):179-81

25. Rodeheaver GT, Ratliff (2008) Wound cleansing, wound irrigation, wound disinfection. In: Krasner D, Rodeheaver G, Sibbald RG (eds) Chronic wound care, Chapter 34. HMP Communications, Malvern

26. Chisholm CD, Cordell WH, Rogers K, Woods JR (1992) Comparison of a new pressurized saline canister versus syringe irrigation for laceration cleansing in the emergency department. Ann Emerg Med 21(11):1364-1367

27. Grotz MR, Allami MK, Harwood P, Pape HC, Krettek C, Giannoudis PV (2005) Open pelvic fractures: epidemiology, current concepts of management and outcome. Injury 36(1):1-13

28. Fernandez R, Griffiths R (2008) Water for wound cleansing. Cochrane Database Syst Rev 23(1):CD003861

29. Khan MN, Naqvi AH (2006) Antiseptics, iodine, povidone iodine and traumatic wound cleansing. J Tissue Viability 16(4):6-10

30. Watt BE, Proudfoot AT, Vale JA (2004) Hydrogen peroxide poisoning. Toxicol Rev 23(1):51-57

31. Cartotto RC, Peters WJ, Neligan PC, Douglas LG, Beeston J (1996) Chemical burns. Can J Surg 39(3):205-211

32. Lee CK, Hansen SL (2007) Management of acute wounds. Clin Plast Surg 34:685-696

33. Tetanus and tetanus toxoid: epidemiology and prevention of vaccine-preventable diseases. National Immunization Program Centers for Disease Control and Prevention. Center for Disease Control Web site. As found at: http://www.cdc.gov/vaccines/vpd$\mathrm{vac} / \mathrm{tetanus} /$ default.htm\#top accessed on 2/25/2009.

34. Eron LJ (1999) Targeting lurking pathogens in acute traumatic and chronic wounds. J Emerg Med 17(1):189-195

35. Hankin A, Everett WW (2007) Are antibiotics necessary after incision and drainage of a cutaneous abscess? Ann Emerg Med 50(1):49-51

36. Edlich RF, Rodeheaver GT, Morgan RF et al (1988) Principles of emergency wound management. Ann Emerg Med 17:1284-1302

37. Ichikawa S, Ishihara M, Okazaki T et al (2007) Prospective study of antibiotic protocols for managing surgical site infections in children. J Pediatr Surg 42(6):1002-1007

38. Farion KJ, Osmond MH, Hartling L et al (2003) Tissue adhesives for traumatic lacerations: a systematic review of randomized controlled trials. Acad Emerg Med 10(2):110-118

39. Lloyd JD, Marque MJ, Kacprowicz RF (2007) Closure Techniques. Emerg Med Clin North Am 25(1):73-81

40. Fonder MA, Mamelak AJ, Lazarus GS, Chanmugam A (2007) Occlusive wound dressings in emergency medicine and acute care. Emerg Med Clin North Am 25(1):235-242 
41. Davidson JM, Breyer MD (2003) Inflammatory modulation and wound repair. J Invest Dermatol 120(5):xi-xii

42. Sibbald RG, Orsted H, Schultz GS, Coutts P, Keast D (2003) International Wound Bed Preparation Advisory Board, Canadian Chronic Wound Advisory Board. Preparing the wound bed 2003: focus on infection and inflammation. Ostomy/Wound Manage 49(11):23-51

43. Sibbald RG, Orsted HL, Coutts PM, Keast DL (2007) Best practice recommendations for preparing the wound bed: update 2006. Adv Skin Wound Care 20:390-405

44. Sibbald RG, Williamson D, Orsted HL et al (2000) Preparing the wound bed: debridement, bacterial balance and moisture balance. Ostomy/Wound Manage 46(11):14-35

45. Stone S, Carter WA (2004) Wound preparation. In: Tintinalli JE, Kelen GD, Stapczynski JS, Ma OJ, Clin DM (eds) Tintinalli's emergency medicine. The McGram-Hill Companies, Inc, New York, pp 284-287

Bret A. Nicks is an Assistant Professor of Emergency Medicine at Wake Forest University with personal interests in clinical education, emergency medicine operations and administration, and global health with a focus on development of infrastructurally appropriate EM internationally. He will be completing an MHA in Global Public Health at the University of North Carolina's Gillings School of Global Public Health in 2010.

Elizabeth A. Ayello is a member of the Clinical Faculty, Excelsior College of school Nursing, Albany, NY.

Kevin Woo is a menber of the Clinical Facuilty, University of Toronto School of Nursing, Toronto, Ontario, Canada.

Diane Nitzki-George is a Clinical Pharmacologist, NorthShore University Health System, Chicago IL.

R. Gary Sibbald is Professor of Public Health Sciences and Medicine, University of Toronto, Toronto, Ontario, Canada, and is the current President of the World Union of Wound Healing Societies, Toronto. 